EESTI NSV TEADUSTE AKADEEMIA TOIMETISED. XIII KÖIDE

FOOSIKA-MATEMAATIKA- JA TEHNIKATEADUSTE SEERIA. 1964, NR. 'I

ИЗВЕСТИЯ АКАДЕМИИ НАУК ЭСТОНСКОЙ ССР. ТОМ ХІІ

СЕРИЯ ФИЗИКО-МАТЕМАТИЧЕСКИХ Н ТЕХНИЧЕСКИХ НАУК. 1964, 1

\title{
KAMBERAHJUDES TOODETUD POLEVKIVIÕLI AROMAATSETE ÜHENDITE KEEMILISEST KOOSTISEST
}

\section{ARRO}

Aromaatsed süsivesinikud on tähtsaks tooraineks mitmesuguste vaikude, plastmasside värvide jne. tootmisel. Aromaatsete ühendite hulk koksitööstuses ei ole enam küllaldane rahuldama tänapäeva keemiatōōstuse nõudeid. Seetõttu on tekkinud vajadus avastada ning uurida ka teisi tooraineliike. Baasiks aromaatsete ühendite tootmisele Eesti NSV-s on pōlevkivitööstus. Mitmesugustest pōlevkivi utteproduktidest sisaldab kōige enam aromaatseid ühendeid kamberahjudes toodetud põlevkiviōli.

Seni on kamberahjudes toodetud vedelate utteproduktide süsivesinikosa keemilise koostise uurimisel piirdutud peamiselt gaasbensiini analüüsiga $\left[{ }^{1}, 2,3,\right]$. Óli raskemast osast on määratud ainult üksikuid komponente $\left[{ }^{4}-9\right]$. Süstemaatilise analüüsi kohta puuduvad andmed.

Käesoleva töö eesmärgiks on määrata kamberahjudes toodetud põlevkiviõli grupiline koostis ja iseloomustada aromaatseid süsivesinikke nende keemilise koostise järgi. Aromaatsete süsivesinike analüüs teostati kahes osas: 1) alküülbensoole, naftaliini, metüülnaftaliine ja dimetüülnaftaliine, mis keemiatööstuse toorainena on olulisemad, uuriti gaasikromatograafiliselt ja mäărati nende individuaalkoostis; 2) kõrgemal temperatuuril keevaiđ fraktsioone analüüsiti ōhukesekihilise kromatograafia ja ultraviolettspektromeetria abil ning identifitseeriti tähtsamad aromaatsed struktuurid.

\section{Eksperimentaalne osa}

Analüüsimisele võeti kamberahjudes toodetud põlevkiviõli, mille füüsikalis-keemiline karakteristika oli jărgmine:

$$
\begin{array}{rcc}
\text { erikaal } & d_{20}^{20} & 1,0336 \\
\text { murdumisnäitaja } & n_{D}^{20} & 1,6885 \\
\text { etementaarkoostis, } \%: & \text { H } & 7,54 \\
\text { C } & 85,9 \\
\text { S } & 0,91 \\
\text { O+N } & 5,65
\end{array}
$$

Oli üldise grupilise koostise määramiseks, olenevalt keemistemperatuurist, destilleeriti algproov kaheksaks fraktsiooniks (tab. 1). Viimased analüüsiti silikageelil kromatografeerimisega $\left[{ }^{10}\right]$, kusjuures kergemad fraktsioonid $(\mathrm{I} \div \mathrm{V})$ defenoleeriti eelnevalt $20 \%$-lise $\mathrm{NaOH}$ resilahusega. Tulemused esitatakse tabelis 1 .

Kromatografeerimisel eraldunud aromaatsete ühendite kontsentraadid destilleeriti. Fraktsioonide $I \div I V$ puhul kasutati 60 teoreetilise taldrikulise lahutusvõimega täidıskolonni, fraktsioonide $\mathrm{V} \div \mathrm{VIII}$ puhul 25 teoreetilise taldrikulist roteeruva südamikuga kolonni. Destillatsioonil vōeti fraktsioonid koguses $0,1 \div 0,15 \%$ algōlist. Saadud alafrakt- 
Kamberahjudes toodetud põlevkiviõli grupiline koostis

\begin{tabular}{|c|c|c|c|c|c|c|c|c|c|c|c|}
\hline \multirow{3}{*}{$\begin{array}{l}\text { Frakt- } \\
\text { sioon }\end{array}$} & \multirow{3}{*}{$\begin{array}{l}\text { Keemis- } \\
\text { piirid, }{ }^{\circ} \mathrm{C}\end{array}$} & \multicolumn{2}{|c|}{$\begin{array}{l}\text { Fraktsiooni } \\
\text { hulk, \% }\end{array}$} & \multicolumn{4}{|c|}{$\begin{array}{l}\text { Destillaadi fraktsioonide } \\
\text { grupiline koostis, \% }\end{array}$} & \multicolumn{4}{|c|}{$\begin{array}{c}\text { Kogu destillaadi grupiline } \\
\text { koostis, } \%\end{array}$} \\
\hline & & \multirow[b]{2}{*}{$\begin{array}{l}\text { alg- } \\
\text { ollist }\end{array}$} & \multirow{2}{*}{$\begin{array}{l}\text { kogu } \\
\text { destil- } \\
\text { laadist }\end{array}$} & \multicolumn{3}{|c|}{ Süsivesinikud } & \multirow{2}{*}{$\begin{array}{l}\text { O+S- } \\
\text { ühen- } \\
\text { did }\end{array}$} & \multicolumn{3}{|c|}{ Süsivesinikud } & \multirow{2}{*}{$\begin{array}{l}\mathrm{O}+\mathrm{S}- \\
\text { ühen- } \\
\text { did }\end{array}$} \\
\hline & & & & $\begin{array}{l}\text { para- } \\
\text { fiinsed }\end{array}$ & \begin{tabular}{c|c} 
ole- \\
fiinsed
\end{tabular} & $\begin{array}{c}\text { aro- } \\
\text { maat- } \\
\text { sed }\end{array}$ & & $\begin{array}{l}\text { para- } \\
\text { fiinsed }\end{array}$ & $\begin{array}{l}\text { ole- } \\
\text { fiinsed }\end{array}$ & $\begin{array}{l}\text { aro- } \\
\text { maat- } \\
\text { sed }\end{array}$ & \\
\hline 1 & & 3, & 4, & & 43,9 & 3 & \multicolumn{2}{|c|}{2,20} & 1,86 & \\
\hline II & 160 & 7,03 & 9,78 & 17,3 & 12,3 & & & 1,69 & 1 & & \\
\hline 11 & $210 \div 255$ & 18,26 & 25 , & 18 , & 11, & & 18 & 4 , & 2, & 13 & 4,61 \\
\hline IV & $255 \div 312$ & 12,54 & 17 , & 5,2 & 4 & 58 & 32 & & 0 , & & 5,69 \\
\hline & $312 \div 370$ & 8, & 11, & 1,9 & 8 & & & 0,2 & 0 , & 6,02 & 5,04 \\
\hline VI & $370 \div 405$ & 11,02 & 15 & 1,2 & 2,2 & 40 & 56 & 0 , & 0,34 & 6,14 & 8,68 \\
\hline VII & $405 \div 5$ & & 10 & 1,3 & & & & & - & & 4,46 \\
\hline & $530 \div 582$ & 4,18 & 5,0 & 2,0 & & 57,9 & & 0,12 & & 3,36 & 2,33 \\
\hline
\end{tabular}

sioonide madalamal temperatuuril keeva osa koostis määrati gaasikromatograafiliselt. Kuni $180^{\circ}$ keemistemperatuuriga ühendid identifitseeriti $6,8 \mathrm{~m}$ pikkuses kolonnis, mille täidise püsiva vedelfaasi moodustas $\beta, \beta^{\prime}$-tiodipropionitriil ja tahkeks kandjaks oli diatomiittellisepuru. Naftaliini piirkonna ühendid, keemistemperatuuriga kuni $273^{\circ}$, analüüsiti $3,8 \mathrm{~m}$ pikkuses kolonnis, mis oli täidetud glükooli ja ftaalhappe polüestriga immutatud diatomiittellisepuruga. Gaasikromatograafilise analüüsi tulemused esitatakse tabelis 2.

Aromaatsete süsivesinike, keemispiiridega $273 \div 582^{\circ}$, analüüsimiseks kromatografeeriti vastavad alafraktsioonid ōhukesel kihil Adsorbendina kasutati alumiiniumoksiidi ja ilmutava lahustina petrooleetri ning kloroformi segu vahekorras 16:1-9:1. Eraldatud kromatograafiliste fraktsioonide valdavad aromaatsed konjugatsioonid määrati spektraaianalüütiliselt [ $\left.{ }^{11}\right]$.

Saadud tulemuste ja tabeli 2 andmete alusel arvutati kamberahjudes toodetud pōlevkiviōli kuni $582^{\circ}$-ni keeva osa keemiline koostis valdavate aromaatsete konjugatsionnide järgi. Arvutuse resultaadid esitatakse tabelis 3.

\section{Katsetulemuste arutelu}

Katsetest selgub, et kamberahjudes toodetud pōlevkiviőli fraktsioonis, keemistemperatuuriga kuni $582^{\circ}$, on peakomponentideks aromatsed süsivesinikud $(44,5 \%)$. Hapniku- ja väävelühendeid sisaldub $35,4 \%$, parafiinseid ja tsükloparafiinseid süsivesinikke $8,4 \%$, olefiinseid ja tsükloolefiinseid süsivesinikke $7,4 \%$.

Aromaatsetest süsivesinikest on sisalduse poolest esikohal naftaliin koos derivaatidega. Peamine naftaliinsete süsivesinike hulk on koondunud fraktsiooni, keemispiiriga kuni $273^{\circ}$. Keemistemperatuuri tõusuga suureneb fraktsioonis naftaliini derivaatide arv, kusjuures monosubstitueeritud naftaliinide puhul on eelistatuks 2 -asendus.

Kondenseerumata tuumadega ja ühetuumialiste aromaatsete süsivesinike fraktsioonist moodustavad suurema osa mitmesugused alküülbensoolid, kusjuures difenüülrea ühendite sisaldus on väike. Keemistemperatuuri tõusuga suureneb bensooli alküülderivaatide arv. Derivaatide puhul on eelistatuks 1,2- ja 1,2,4-asendused.

Kõrgemal temperatuuril keevas osas esinevad aromaatsete süsivesinike peakomponentidena antratseen ja püreen koos derivaatidega. Ohukesekihilisel kromatografeerimisel saadud fraktsioonide spektraalsetest määramistest võib järeldada, et uuritud piirkonnas ei ole aromaatseil süsivesinikel tugevalt konjugeeritud külgahelad tüüpilised.

Heterotsükliliste difenüleenoksiidi tüüpi ühendite käsitlemist hapnikuühenditest eraldi tingis nende suurem sarnasus aromaatsete süsivesinikega (kromatograafilise analüüsi seisukohast). Difenüleenoksiidi identifitseerimine pōlevkiviōlis omab tähtsust selle tõttu, et ta võimaldab osaliselt seletada õlis esinevate neutraalsete hapnikuühendite struktuuri. 
Kamberahjudes toodetud põlevkiviõli fraktsiooni, keemistemperatuuriga $\div 273^{\circ}$, keemiline koostis

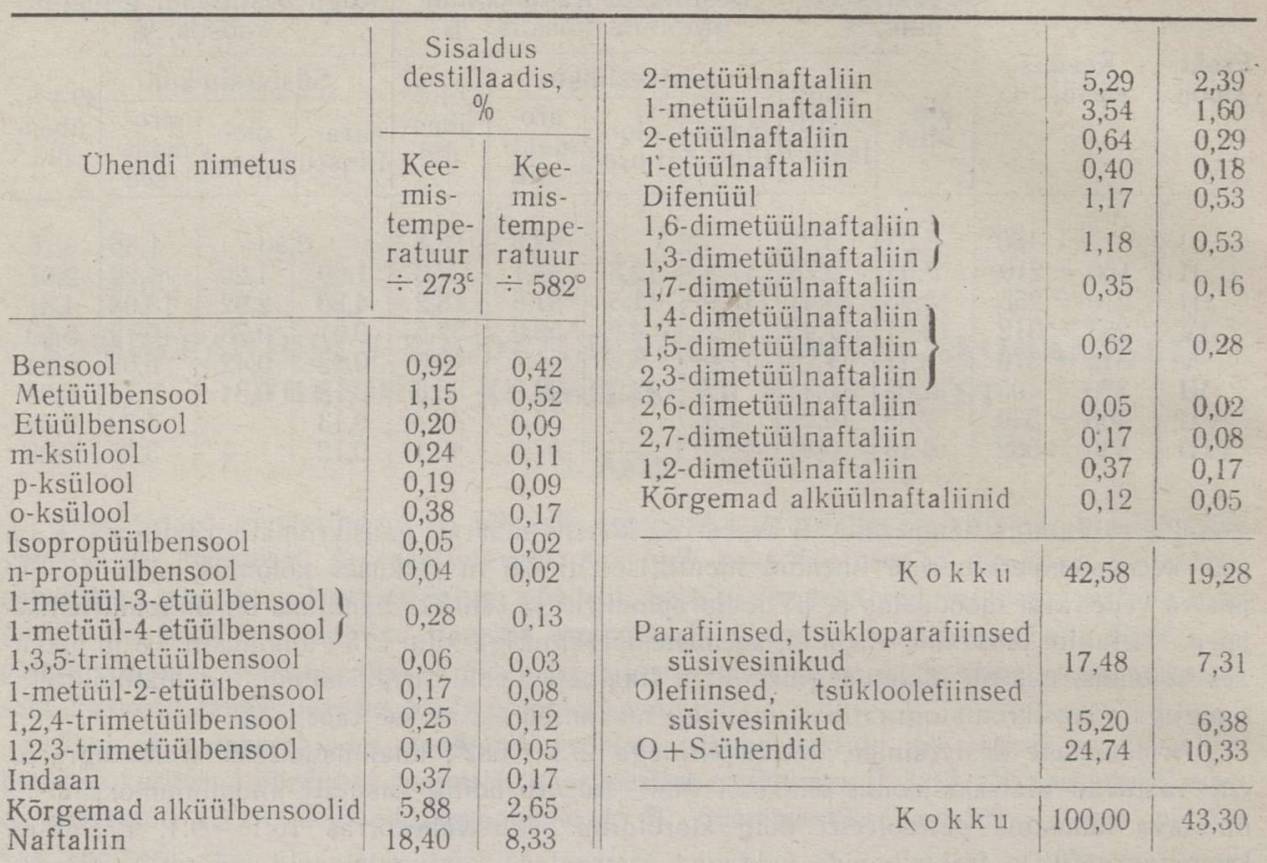

Kamberahjudes toodetud põlevkiviōli fraktsiooni, keemistemperatuuriga $\div 582^{\circ}$, keemiline koostis

\begin{tabular}{|c|c|c|}
\hline \multirow[b]{2}{*}{ Fraktsiooni pōhiline struktuur } & \multicolumn{2}{|c|}{ Sisaldus, $\%$} \\
\hline & $\begin{array}{l}\text { destillaadis } \\
\text { keemistem- } \\
\text { peratuuriga } \\
\quad \div 582^{\circ}\end{array}$ & algõlist \\
\hline $\begin{array}{l}\text { Kondenseerumata tuumadega ja monotsükliline } \\
\quad \text { aromaatika } \\
\text { Difenüleenoksiid } \\
\text { Naftaliin } \\
\text { Fluoreen } \\
\text { Antratseen, fenantreen } \\
\text { Püreen } \\
\text { Krüseen } \\
\text { 1,2-bensantratseen } \\
\text { 3,4-benspüreen, bensperüleen } \\
\text { Määramata struktuuriga aromaatika }\end{array}$ & $\begin{array}{r}5,54 \\
0,44 \\
22,23 \\
0,93 \\
7,07 \\
5,09 \\
0,43 \\
0,52 \\
1,11 \\
1,21\end{array}$ & $\begin{array}{r}3,98 \\
0,32 \\
15,94 \\
0,67 \\
5,08 \\
3,65 \\
0,31 \\
0,38 \\
0,80 \\
0,88\end{array}$ \\
\hline Kok ku & 44,57 & 32,01 \\
\hline $\begin{array}{l}\text { Parafiinsed, tsükloparafiinsed, süsivesinikud } \\
\text { Olefiinsed, tsükloolefiinsed süsivesinikud } \\
\text { O+S-ühendid. }\end{array}$ & $\begin{array}{r}8,41 \\
7,40 \\
35,43\end{array}$ & $\begin{array}{r}6,04 \\
5,31 \\
25,41\end{array}$ \\
\hline Kaod analüüsil & $\begin{array}{r}95,81 \\
\quad 4,29 \\
\end{array}$ & $\begin{array}{r}68,77 \\
3,08 \\
\end{array}$ \\
\hline $\mathrm{Kokku}$ & 100,00 & 71,85 \\
\hline
\end{tabular}


Hapnikuühendite fraktsioonis esinevad fenoolid kui oksiaromaatsed ühendid peaksid termodünaamilistest kaalutlustest !ähtudes olema tuumade konjugatsiooni järgi ligikaudu samasuguse struktuurilise jaotusega kui aromaatsete ühendite süsivesinikosagi.

Parafiinsed ja olefiinsed süsivesinikud, mis on koondunud peamiselt madalamal temperatuuril keevaisse fraktsioonidesse, moodustavad uuritud õli koostisest niivõrd väikese osa, et kamberahjudes toodetud pōlevkiviōli kasutussuundade määramisel keemiatööstuse toorainena ei oma nad otsustavat tähtsust. Seega pakub olefiinsete ja parafiinsete süsivesinike täpsem uurimine rohkem teoreetilist kui praktilist huvi.

Tehtud tööst võib järeldada, et kamberahjudes toodetud pōlevkiviõli kasutamine toorainena peenkeemiatööstuses ei ole tõenäoliselt eriti perspektiivne, sest õli keeruline koostis ei võimalda tööstuslikes kogustes eraldada küllaldase puhtusastmega sünteesi lähteprodukte.

Suur naftaliini ja fema alküülderivaatide sisaldus õlis loob eeldusi madalamal temperatuuril keevate fraktsiononide kasutamiseks ftaalhappe anhüdriidi tootmiseks [ $\left.{ }^{12}\right]$.

Kõrgemal temperatuuril keevates õlifraktsioonides esinevad komponendid, nagu püreeni ja antratseeni jne. struktuuriga aromaatsed ühendid, on sobivaks tooraineks elektroodkoksi tootmisel $\left[{ }^{13}\right]$.

\title{
K I R J A N D S
}

1. Кобыльская М. В., С еменов С. С., Глушенков а Е. В., Шульман $3 . \Phi$. Химия и технология горючих сланцев и продуктов их переработки, вып. 7 , Л., Гостоптехиздат, 1959, стр. 207.

2. Klesment I., Arume 1 E. ENSV TA Toimet. Tehn. ja Füüs-matem. Tead. Seeria, 1959, nr. 3, $1 \mathrm{k} .181$.

3. Arro I., E isen O. ENSV TA Toimet. Tehn. ja Füüs.-matem. Tead. Seeria, 1960, nr. $3,1 \mathrm{k} .187$

4. Томина Е. И., Че рны шев а К. Б., Д емен тьев а Е. М. Химия и технология горючих сланцев и продуктов их переработки, вып. 2, Л., Гостоптехиздат, 1954, стр. 145.

5. Eisen O., Arro I. ENSV TA Toimet. Tehn. ja Füüs.-matem. Tead. Seeria, 1958, nr. $3,1 \mathrm{k}, 220$.

6. Эй зен О. Г., А р ро И. Х. Вопр. онкологии, т. 5, 1959, № 3, стр. 160.

7. Эйз ен О. Г., А р ро И. Х., Богов ский П. А. Ннститут химии АН ЭССР, Горючие сланцы, вып. 4, 1961, стр. 191.

8. Дикун П. П., М ахиненко А. И. Гигиена и санитария, 1963, № 1, стр. 10.

9. Г удя в а Л. И., Пы шкин а Н. И. Химия и технология горючих сланцев и продуктов их переработки, вып. 5, Л., Гостоптехиздат, 1956, стр. 217.

10. E b y L. T. Anal. Chem., vol. 25, 1953, p. 1057.

11. Брукс Б. Т., Бура С. Б., Куртц С. С., Шмерлинг Л. А. Химия и технология углеводородов нефти I, 1958, стр. 278.

12. М а д с с он Э. Х. Горючие сланцы ГНТК СМ ЭССР, 1962, № 2, стр. 47.

13. Кожевников А. В., Боговски ӥ П. А., Горталум Г. А. Изв. АН ЭССР. Сер. биолог., № 3, 1961.

Eesti NSV Teaduste Akadeemia Keemia Instituut
Saabus toimetusse

2. X 1963

\section{O ХИМИЧЕСКОМ СОСТАВЕ АРОМАТИЧЕСКИХ СОЕДИНЕНИИ СЛАНЦЕВОЙ СМОЛЫ КАМЕРНЫХ ПЕЧЕИ}

\author{
И. Appo \\ Резюме
}

В настоящей работе нсследовался химический состав ароматических углеводородов сланцевой смолы с температурой кипения до $582^{\circ}$ С. Пользуясь данными газохроматографин, определялся индивидуальный состав соединений, кипящих до $273^{\circ}$. Для анализа высококипящнх компонентов использовались тонкослойная хроматография и спектральнын̆ анализ в ультрафнолетовой областн. 
В результате анализов установлено, что главным компонентом низкокипящей части сланцевой смолы камерных печей является пафталнн н его пронзводные, высококипящей части - антращен, фенантрен н соединения типа пирена.

В результате спектральных исследований установлено, что сильно конъюгнрованная боковая цепь не является характерной для ароматических углеводородов сланцевой смолы. Цля алкилированной ароматики характерна боковая цепь 1,2- н 1,2,4-положения, а для монозамешенных нафталинов 2-положения.

Приведенные в работе данные дают возможность оценить сланщевую смолу камерных печей в качестве сырья для химической промышленности.

Ннститут хинии

Академии наук Эстонской ССР
Поступнла в редакцніо 2. X 1963

\section{ON THE CHEMICAL COMPOSITION OF AROMATIC COMPOUNDS OF SHALE OIL OBTAINED IN CHAMBER OVENS}

\section{Arro}

\section{Summary}

A study was made of aromatic hydrocarbons of shale oil obtained in chamber ovens and having a boiling point of up to $582^{\circ} \mathrm{C}$. The individual composition of compounds boiling at up to $273^{\circ} \mathrm{C}$ was defined by gas-chromatographic methods. At the aualysis of hydrocarbons with higher boiling points, methods of thin-layered chromatography and ultraviolet spectral analysis were applied, with the help of which the most-occurring aromatic structures were identified.

As a result it was stated that the main component of shale oil boiling at lower temperatures is naphthalene together with its derivatives, and of oil boiling at higher temperatures - compounds of anthracene, phenanthrene and pyrene type. The spectrometric measurements revealed that strongly conjugated side chains are not typical of shale oil aromatic compounds. In case of alkylbenzene, the 1,2- and 1,2,4-arrangements are the prevailing ones, and in case of naphthalene - the 2-arrangements.

The data obtained are a basis for an evaluation of chamber-oven shale oil as a raw material for the chemical industry.

Academy of Sciences of the Estonian S.S.R., Received Institute of Chemistry 